\title{
EL PACTISMO COMO ELEMENTO FUNDAMENTAL DE LA FORALIDAD
}

\author{
Santiago Larrázabal Basáñez \\ Profesor de Derecho Constitucional \\ y Director del Instituto de Estudios Vascos de la Universidad de Deusto
}

Sumario: 1. Dedicatoria. 2. Introducción. 3. El pactismo en el Señorío de Bizkaia. 4. El pactismo en la Provincia de Gipuzkoa. 5. El pactismo en la Provincia de Alava. 6. La pervivencia del pacto en la tradición foral de Bizkaia, Gipuzkoa y Alava. 7. El pactismo en el Reino de Navarra. 8. Reflexión final.

\section{Dedicatoria}

Como discípulo del Profesor Dr. D. Pablo Lucas Verdú, constituye para mi una ineludible obligación y al mismo tiempo un gran honor tomar parte en este número monográfico de la Revista «Estudios de Deusto» a él dedicado, en el marco del homenaje que la Facultad de Derecho de la Universidad de Deusto ha querido tributarle en reconocimiento a sus muchos años de impagables servicios a la Facultad y a nuestra Universidad.

La Facultad nos ha encomendado a los miembros del Departamento de Derecho Constitucional y Administrativo la preparación de dicho homenaje y me siento muy honrado de colaborar en él, tanto como miembro del Comité organizador del mismo como a través de este trabajo que tiene usted entre sus manos.

Sean estas líneas testimonio de mi profunda gratitud y admiración hacia un gran estudioso de la ciencia política y del derecho constitucional a quien, para mi fortuna, tengo por maestro y, sobre todo, por amigo.

\section{Introducción ${ }^{1}$}

El objeto de este artículo es analizar el «pacto» como fundamento del autogobierno vasco en la época foral clásica. Para ello, estudiaré

\footnotetext{
${ }^{1}$ Respecto al pactismo pueden consultarse: Aranguren y Sobrado, F., Demostración del sentido verdadero de las autoridades de que se vale el doctor D. Juan Antonio Llorente, Universidad del País Vasco, Bilbao, 1994, pp. 251-289 y 429-473; ArTiÑANo ZuRI-
} 
CAlday, A., El Señorío de Bizcaya, histórico y foral., La Peninsular, Barcelona, 1885, pp. VI-X; AA.VV., Simposio sobre el Pactismo en la Historia de España, celebrado los días 24-26 de abril de 1978 en el Instituto de España, Cátedra Francisco de Vitoria, Madrid, 1980; AA.VV., «El mito foral en la historiografía navarra contemporánea», Boletín del Instituto Gerónimo de Uztariz, Pamplona, 2 (1988), pp. 5-60; ARTOLA, M., «El entramado foral». Antonio Elorza entrevista a Miguel Artola, Dossier: «País Vasco y Castilla, ocho siglos de unión», La aventura de la historia, Año 2, n. 22 (agosto 2000), pp. 62-68; BASURTO LARRAÑAGA, R., «Elementos neoclásicos y prerrománticos en la historiografía vasca de principios del siglo XIX: J.A. de Zamácola», Revista Internacional de Estudios Vascos, año 34, Tomo XXXI-3 (1986), pp. 661-675; Burgo Tajadura, J.I. del, Curso de Derecho Foral, op. cit., pp. 47-51, 78-79 y 84-86; CANELlas. A., «De la incorporación de Guipúzcoa a la Corona de Castilla», España medieval, 3 (1982), pp. 11-19; CARO BAROJA, J., Los vascos y la historia a través de Garibay, Ed. Txertoa, San Sebastián, 1972, p. 374; ElorZA, A., «De la historia al mito», Dossier: «País Vasco y Castilla, ocho siglos de unión», La aventura de la historia, Año 2, n. ${ }^{\circ} 22$ (agosto 2000), pp. 54-61; Estornés Zubizarreta, I., Voz «Pactismo», Diccionario Enciclopédico Vasco, Ed. Auñamendi, San Sebastián, 1993, volumen XXXV, pp. 428-431; FonTECHA y SAlAZAR, P., Escudo de la más constante fe y lealtad, La Gran Enciclopedia Vasca, Bilbao, 1976, pp. 19-89; GARCía GALlo, A., «El pactismo en el Reino de Castilla», en AA.VV., Simposio sobre el pactismo, op. cit.; GonZÁlEZ ARNAO, J., voz «Vizcaya» en Diccionario histórico geográfico de España por la Real Academia de Historia, Madrid, 1802; GoYhenetche, J., Les basques et leur histoire. Mythes et realités, Elkar, Donostia, 1993; JuARIsti, J., La leyenda de Jaun Zuria, Caja de Ahorros Vizcaína, Bilbao, 1980; JuARISTI, J., «Los mitos de origen en la génesis de las identidades nacionales. La batalla de Arrigorriaga y el surgimiento del particularismo vasco (siglos XIV-XVI)», Studia Histórica. Historia Contemporánea, 12 (1994), pp. 191-228; LACARRA, J.M. ${ }^{a}$, «El Juramento de los Reyes de Navarra (1234-1329)», Discurso de ingreso en la Real Academia de Historia, Universidad de Zaragoza, Departamento de Historia Medieval, Zaragoza, 1972; LACARRA, J.M. ${ }^{a}$, «El pactismo navarro», en «Las Cortes medievales. Parte V», Historia 16, Año I, n. 5 (septiembre de 1976), pp. 87-91; LACARRA, J.M. a, «Estructura político-admnistrativa de Navarra antes de la Ley Paccionada», Príncipe de Viana, $92-93$ (1963), pp. 231-248; LARRAZÁBAL BASÁÑEZ, S., Contribución a una teoría de los derechos históricos vascos, Instituto Vasco de Administración Pública, Oñati, 1997; LARRAZÁBAl BASÁÑEZ, S., La foralidad de Bizkaia, Juntas Generales de Bizkaia, Bilbao, 2001, pp. 28-31; LARrea SAGARMínAGA, M. ${ }^{2}$ A., «La teoría foral en el siglo XVIII», en II Congreso Mundial Vasco. Los Derechos Históricos Vascos, Instituto Vasco de Administración Pública, Oñati, 1998, pp. 53 y ss.; LEGAZ y LACAMABRA, L., Filosofía del pactismo, en AA.VV., El pactismo en la Historia de España, op. cit.; LIÑÁN Y Eguizabal, J. de, La Jura de los Fueros por los Señores de Bizkaya. Su trascendencia histórica y social, Bilbao, 1897, pp. 9-87; LÓPEZ ATXURRA, R., «La foralidad en la historiografía vasca», Ernaroa, 6 (1991), pp. 117-170; LloRENTE, J.A., Noticias históricas de las tres Provincias Vascongadas, Editorial de Amigos del Libro Vasco, Bilbao, 1984, pp. 33-59; MAÑARICÚA Nuere, A. E. de, Historiografía de Vizcaya. Desde Lope García de Salazar a Labayru,

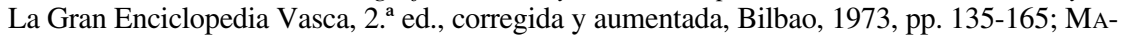
Richalar, A./ManriQue, C., Historia de los Fueros de Navarra, Vizcaya, Guipúzcoa y Alava, 2. ${ }^{a}$ ed. corregida y aumentada, ed. facsímil, Ed. Auñamendi, San Sebastián, 1971, pp. 246-265 (Bizkaia), pp. 345 y ss. (Gipuzkoa); pp. 468-488 (Alava); pp. 119-156 (Navarra); MONREAL ZíA, G., «Anotaciones sobre el pensamiento político tradicional vasco en el siglo XVI», Anuario de Historia del Derecho Español, L (1980), pp. 971-1004; MonREAL ZÍA, G., «Incidencia de las instituciones públicas de Alava del medievo en el pensamiento político de los alaveses de la Edad Moderna», Anuario de Historia del Derecho, 54 (1984), pp. 613-638; MonReal Zía, G., «Entidad y problemas de la cuestión de los derechos históricos vascos», en Jornadas de Estudio sobre la actualización de los Derechos Históricos, Universidad del 
los orígenes del «pactismo» en cada uno de los Teritorios Forales, centrándome, sobre todo, en la época foral clásica, para concluir con una brevísima reflexión acerca de lo que el «pactismo» puede aportar al contexto jurídico-político de hoy.

Como decía anteriormente, uno de los elementos básicos de la foralidad que aún hoy subyace en las relaciones entre los territorios forales y el Estado central es, sin duda alguna, el pactismo. Cuando, por ejemplo, analizamos en profundidad el Estatuto de Autonomía de Gernika, la Ley Orgánica de Reintegración y Amejoramiento del Régimen Foral de Navarra, el Concierto Económico vasco o el Convenio navarro, este substrato «pactista» aparece por doquier, lo que singulariza claramente a los Territorios Forales diferenciándolos de otros de régimen común.

Como ha escrito el profesor Gregorio $\mathrm{Monreal}^{2}$, antes de que se consolidase el absolutismo (un sistema en el que el Rey era el titular supremo y exclusivo del poder), existieron otras concepciones sobre la relación entre el Rey y la comunidad como, por ejemplo, la pactista. Esta última tenía su fundamento en un sistema bipolar: por un lado, se encontraba el Rey o Señor (hereditario o electivo) como depositario de un poder constituido y por el otro, la Colectividad (representada en las Asambleas de los sectores sociales más poderosos de la comunidad), que tenía a su vez sus propios poderes, poderes que cedía al Monarca,

País Vasco, 1986, pp. 47-82; NAEF, W., La idea del Estado en la Edad Moderna, Aguilar, Madrid, 1973, pp. 15 y ss. y 102 y ss.; NAVASCUÉs, R. de, Observaciones sobre los Fueros de Vizcaya, Madrid, 1850, pp. 57-67; Novia DE SAlCEDO, P., Defensa histórica, económica y legislativa del Señorío de Vizcaya y Provincias de Alava y Guipúzcoa, Bilbao, 1851,Tomo III, pp. 112-163; OlAVE y DíEZ, S., El pacto político como fundamento histórico general de la nacionalidad española y especialmente como manifestación legal de la soberanía independiente de Navarra en unas épocas y en otras de su autonomía sin perjuicio de la unidad nacional, Madrid, 1878; ORELla, J.L., Las instituciones del Reino de Navarra en la Edad Antigua y Media. Las instituciones de la Baja Navarra (1530-1620), San Sebastián, 1991, pp. 81-86 y 90-95; OrtiZ de ZÁrate, R., Compendio foral de la Provincia de Alava, Caja de Ahorros Municipal de la Ciudad de Vitoria, Vitoria, 1971; p. 129; Portillo ValdÉs, J.M., «Pedro Novia de Salcedo y la Constitución Histórica: la cultura política de la foralidad», II Congreso Mundial Vasco. Congreso de Historia de Euskal Herria, Servicio Central de Publicaciones del Gobierno Vasco, Vitoria-Gasteiz, 1988, Tomo IV, pp. 323-333; SÁnchezArCilla Bernal, J., Historia del Derecho. Instituciones político-administrativas, Ed. Dykinson, Madrid, 1995, pp. 499-503; Tomás y Valiente, F, Manual de Historia del Derecho Español, Ed. Tecnos, Madrid, 3. a ed., 1981, pp. 282-297; VALDEÓn BARUQue, J., «Castilla y los vascos, años 1200», Dossier: «País Vasco y Castilla, ocho siglos de unión», La aventura de la historia, Año 2, n. 22 (agosto 2000), pp. 48-53; VEGA, U.A., «En 1200: Guipúzcoa y Castilla ¿la Unión fue voluntaria o forzosa?», Euskalerriaren alde, 16 (1926), pp. 66-70.

2 Monreal Zía, G., «Incidencia de las instituciones públicas de Alava del medievo...», op. cit., pp. 619 y ss. La cita de GARCía GALlo, correspnde a su Historia del Derecho español. I. El origen y la evolución del Derecho, Madrid, 1979, núms. 1303-1315. 
en parte y bajo condiciones. De este modo, la unión del Rey o Señor y de los representantes de los distintos estamentos de la Comunidad constituía el sistema de gobierno y, por ende, cualquier decisión relativa al mismo requería el consentimiento de ambas partes. Decía García Gallo que el Rey era designado por el Reino en virtud de un pacto y estaba revestido de las facultades que expresamente se le otorgaban.

Este fue el contenido sustancial del denominado «pactismo político», que antes de que naciese el modelo absolutista, tuvo una gran difusión por toda Europa y consiguió un especial arraigo en los Estados Pirenaicos (en especial en la Corona de Aragón y en el Reino de Navarra). En nuestro contexto, y en palabras de Monreal: «... el Pacto es el dato político más relevante de la civilización vascónica, hasta el punto de que continúa impregnando la vida pública de los territorios del País Vasco occidental cuando se desgajan de la monarquía navarra y se integran en una monarquía como la castellana, en la que apenas se conoce esa tradición política».

\section{El pactismo en el Señorío de Bizkaia}

En Bizkaia, el pactismo subyace en todo el entramado foral del Señorío. Así, si nos remontamos a su origen mítico, el pacto surge de inmediato a través de la elección del primer Señor. Como ha escrito Monreal $^{3}$, tanto en la versión del conde de Barcelos como en la Lope García de Salazar ${ }^{4}$, el sistema se fundamenta siempre en el pacto entre un caudillo militar y los vizcaínos.

La primera versión, la del conde de Barcelos, se contiene en el tratado genealógico denominado Livro dos Linhagens, escrito por el portugués Pedro Alfonso, conde de Barcelos, entre 1325 y 1344, quien dedica el primer capítulo del título IX al origen de los Señores de Bizkaia. Según este autor, Froom, hermano del Rey de Inglaterra, acompañado de

3 Monreal Zía, G., Ibidem, p. 622.

${ }^{4}$ En relación con este tema pueden consultarse: Balparda, G., Historia crítica..., op. cit., pp. 405 y ss; Catalán, D., De Alfonso X al Conde Barcelos, Ed. Gredos, Madrid, 1962; JuARISTI, J., El linaje de Aitor. La invención de la tradición vasca, Ed. Taurus, Madrid, 1987; García de Salazar, L., Crónica de Siete Casas de Vizcaya y Castilla, publicada por Juan Carlos Guerra en Rivadeneira, Madrid, 1914, pp. 6 y ss.; Bienandanzas e Fortunas, ed. de Angel Rodríguez Herrero, Diputación de Vizcaya, Bilbao, 1967, tomo IV, pp. 7-9; Lindlay, Crónica geral de Espanha, pp. CLXXXIV-CLXXXVI. La edición crítica en Herculano, A, Monumenta Portugaliae Historica. Scriptores I (Lisboa, 1856), pp. 230-290; Monreal Zía, G., Las instituciones públicas..., op. cit., pp. 18 y ss.; MAÑARICÚA NuERE, A. E. de, Historiografía..., op. cit., pp. 151-154. 
su hijo, llegó a Bizkaia y se ofreció a dirigir a sus habitantes en la lucha contra el conde asturiano Don Munio si se le aceptaba como Señor, como así se hizo, librando contra Don Munio la victoriosa batalla de Arrigorriaga. La segunda versión corresponde a Lope García de Salazar quien, tanto en su Crónica de Vizcaya como en sus Bienandanzas e Fortunas, nos describe cómo el Rey de León, asolaba Bizkaia. Al negarse dicho Rey a luchar con los vizcaínos por no estar dirigidos por un Rey o persona de sangre real, éstos tomaron como capitán a Don Zuria (Jaun Zuria), que significa en castellano «Señor Blanco», nieto del Rey de Escocia, quien derrotó al Rey leonés cerca de Bilbao, en Padura, cuyas rocas se tiñeron por ello de rojo con la sangre derramada y reciben desde entonces el nombre de «Arrigorriaga» (en castellano, «pedregal rojo»). La contrapartida fue el pacto de los vizcaínos con el Primer Señor de Bizkaia, Jaun Zuria. Se le entregaron parte de los montes, algunas heredades en todas las comarcas para colocar a sus labradores y se le reconocieron algunos derechos sobre la vena de hierro. A cambio, Jaun $\mathrm{Zu}-$ ria juró los Fueros en Gernika, en unos términos que, según D. Andrés de Mañaricúa, podrían recordar los del Fuero Viejo de Bizkaia.

Este mito de los orígenes del Señorío tenía la función de explicar la peculiar posición política y patrimonial de los Señores de Bizkaia y la privilegiada situación de la comunidad en el sistema político, contribuyendo además a legitimar la práctica pactista que se observaba en el Territorio. Y añade el profesor Monreal: «... no existe comparación posible entre las prescripciones pactistas del Cuaderno de 1394 o el Fuero Viejo de 1452 y cualquier otro cuerpo jurídico peninsular y quizá europeo. Los textos fueron elaborados por Comisiones designadas por toda la comunidad reunida en asamblea y sometidos a su ratificación, expresaban la voluntad del colectivo y estaban inspirados en la idea de que el Señorío está constituido por un pacto permanente y periódicamente manifestado entre la comunidad y el Señor».

En esta misma línea se inscriben las tesis de la independencia originaria de Bizkaia. Según estas teorías, el territorio era libre e independiente y su vinculación a la Corona de Castilla sólo se entiende desde la óptica del pacto. Pacto que le permitió seguir manteniendo su propio sistema jurídico-político y su condición de «nación separada». De la independencia originaria de Bizkaia y de su consideración como nación separada nos hablan Marichalar y Manrique ${ }^{5}$ y así se explica que, por ejemplo, a principios del siglo XVI se le prohibiese a Bizkaia enviar procuradores a las Cortes de Castilla. Parafraseando una vez más al profesor Monreal, esa situación de

5 Cfr. Marichalar, A./Manrique, C., Historia de los Fueros..., op. cit., pp. 247 y 264-265. 
cuasi independencia de Bizkaia y la circunstancia de que buena parte del Señorío (la Tierra Llana) estuviese exenta de la actividad legislativa del Señor, permitió la constitución de una «una suerte de masa crítica de supervivencia» que aseguró la autonomía de la comunidad después de la incorporación a la Corona ${ }^{6}$. Por ello, con la aparición del Condado de Bizkaia en el siglo XI y la figura de Iñigo López, durante el período histórico en que la familia Haro se mantuvo al frente del Señorío y también desde la incorporación del Señorío a la Corona de Castilla en 1379, por coincidir en la persona del Rey Juan I de Castilla los títulos de Señor de Bizkaia y de Rey de Castilla, la idea del pacto nos acompaña siempre.

En esas condiciones de incorporación, el pacto aparece una vez más como elemento nuclear del sistema. Se trata de una unión personal bajo acuerdo entre ambas partes y con un símbolo claro: el juramento de los Fueros por cada nuevo Monarca como Señor de Bizkaia. Así, tanto el Fuero Viejo de 1452 (capítulos I-III) como el Fuero Nuevo de 1526 (Título I, leyes I-III) establecen cómo ha de jurar el Señor de Bizkaia, cómo han de hacerlo sus oficiales (prestameros, merinos...) y qué se ha de jurar ${ }^{7}$. En este mismo sentido, López Atxurra ${ }^{8}$ ha escrito que, «... tal relación de reconocimiento mutuo, tanto de la autoridad del Señor, como de los usos y costumbres de la comunidad (Título I, Ley I del Fuero Nuevo) así como los límites de la autoridad del Señor (Título $1 .^{\circ}$ Leyes VIII-XI),

6 Monreal Zía, G., «El Derecho Histórico Vasco y su originalidad», en Forum Deusto, (cultura vasca), Universidad de Deusto, Bilbao, 1994, p. 136.

7 Según los Fueros vizcaínos, el Rey y Señor de Bizkaia, debía realizar su juramento, primero, a las puertas de la Villa de Bilbao; después, en la iglesia de S. Emeterio y S. Celedonio de Larrabetzu; posteriormente, en Gernika, ante el venerado roble («so el árbol donde se acostumbra hacer la Junta»), símbolo de las libertades de Bizkaia y, por último, en la iglesia de Santa Eufemia de Bermeo. En la propia ceremonia de la jura, el elemento contractual estaba claro: el juramento alcanzaba a los privilegios, libertades, franquezas, usos, costumbres, tierras, mercedes y fueros de los vizcaínos. Si no había juramento, éstos no debían pagar las rentas pedidas, ni obedecer sus cartas, etc. Si lo había, surgían las obligaciones derivadas del pacto foral que se sellaba simbólicamente con el «besamanos» ( «é los vizcainos hanle de recibir é besarle las manos por Señor»), «besamanos», recogido de una manera muy precisa incluso en la literatura castellana de la época. A este respecto, resulta imprescindible consultar el libro del P. Anselmo de LEGARDA, Lo vizcaíno en la literatura castellana, Biblioteca Vascongada de los Amigos del País, San Sebastián, 1953, pp. 395-406. La obra por él citada que recoge con mayor exactitud la ceremonia de la jura, es la del poeta dramático y novelista del siglo XVII y famoso autor de El diablo cojuelo, Luis Vélez de Guevara, El amor en vizcaíno, los Zelos en francés y Torneos de Navarra, folio 5.) y en cuanto a su representación gráfica, tenemos un magnífico testimonio pictórico: el célebre cuadro de Francisco de Mendieta, que plasma muy bellamente cómo las Juntas Generales de Bizkaia, reunidas «so el árbol sagrado», le rinden pleitesía al Rey D. Fernando el Católico tras jurar éste los Fueros el 30 de julio de 1476.

8 LÓPEZ AtXuRRA, R., La administración fiscal del Señorío de Bizkaia (1630-1804), Diputación Foral de Bizkaia/Instituto de Derecho Histórico de Euskal Herria, Bilbao, 1999, p. 71. 
son recogidos en los textos forales, respondiendo este funcionamiento político a la teoría contractual del poder, vigente en el medievo». Esta construcción ideológica fue aceptada tácita o expresamente por la Corona, sancionándola a través de Reales Ordenes y juramentos ${ }^{9}$ y se mantuvo hasta el siglo XVIII.

Sin embargo, hubo también intentos de combatir el «statu quo» de la integración de los territorios forales en la Corona de Castilla, pero ante cada intento de ataque al mismo en pos de un proceso de uniformización, la defensa foral siempre fue la misma: el carácter pactado del sistema. Y así, ante las pretensiones de uniformización del conde-duque de Olivares, valido de Felipe IV, para, como decía en su conocida recomendación al Rey, «reducir, estos reinos de que se compone España, al estilo y leyes de Castilla, sin ninguna diferencia» ${ }^{10}$, las protestas fueron inmediatas. Como muestra de la protesta vasca, y en relación el asunto del estanco de la sal, que violaba flagrantemente la libertad de comercio, uno de los elementos básicos de la foralidad, resulta de gran interés el alegato de Mateo de Echávarri, consultor del Señorío, en 1630, recogido por Juan E. Gelabert: «... toda la tierra, montes, exidos y usos de Vizcaya son de los Vizcaynos, en tanta manera, que aun el suelo de una villa para fundarlo en él no le puede dar, sin que ellos lo consientan [...] Este Señorío es distinto y separado de la Corona de Castilla y no está incorporado a ella ni acude a sus Cortes... en la una Su Majestad es rey y en la otra señor. El vínculo entre el príncipe, por un lado, y Castilla o Vizcaya, del otro, se hace bajo la consideración de aeque principaliter, no per modum accesorii, de manera que cada uno tiene sus leyes. Su Majestad dos personas; es como si estuvieran este Reyno y el Señorío divididos en dos señores diversos y no se puede sostener que las leyes de un reyno pudieran extenderse a otro aunque ambos estén debaxo de un Príncipe ${ }^{11}$.

La profesora María Angeles Larrea ${ }^{12}$ ha sintetizado este planteamiento, recogiéndolo de la Declaración que abre la Exposición de la Diputación del Señorío de Bizkaia a la Corona, de fecha 31 de marzo de 1715, que afirma que los habitantes del país se dotaron de Señores electivos hasta que el mandato se transformó en hereditario, pero «no absoluto, sino con pactos y condiciones». Y como dice el Memorial:

9 Estornés Zubizarreta, I., Voz «Pactismo», op. cit., p. 430.

${ }^{10}$ Los documentos del conde-duque de Olivares relativos a esta época pueden consultarse en Elliot, J.H./DE la PeÑa, J.F., Memoriales y cartas del conde-duque de Olivares, Ed. Alfaguara, Madrid, 1978-1980.

11 Gelabert, J.E., Castilla convulsa (1631-1652), Marcial Pons, Madrid, 2001, p. 52.

12 Larrea Sagarmínaga, M.A., «La teoría foral en el siglo XVIII», op. cit., pp. 59-60 y notas 11-14. 
«Continúose la sucession de mi Señorío en tiempo del Señor Don Juan el Primero, (...) pero esa unión fue con el preciso pacto de guardarme mis Fueros y se han guardado, y guardan...»

En palabras de la profesora vizcaína: «Haciendo las transposiciones necesarias de fechas y de nombres, éste es el canon justificativo manifestado: Independencia primera sostenida, asegurada y testimoniada al tiempo por la permanencia de las costumbres antiguas y del viejo idioma y que, andando el tiempo, se resuelve en la unión a la Corona de Castilla mediante una vinculación libre, con las calidades de igual, principal y respectiva, que D. Pedro de Fontecha y Salazar explicaba anotando que "cada Reyno, Provincia, Pueblo o Iglesia de las que así se unen, se queda con las mismas Leyes, Fueros, privilegios, usos y costumbres que antes tenía, sin otra mistura ni alteración, que de tener un mismo Soberano; pero en todo lo demás retienen su propia naturaleza, como si estuvieran separados baxo del Imperio de diversos Principes, del mismo modo que se mantenían, antes que se huviessen unido por matrimonio, ó derecho de sucesión, ú otro". Y la calidad de respectiva suponía la mutua obligación en la observancia de lo pactado, según los derechos y deberes allí establecidos para las partes contratantes; oneroso, de acuerdo con el vocabulario jurídico del tiempo, para ambos pactantes. Y, para mayor garantía, en el propio Fuero jurado se había establecido la capacidad legal de vetar por cada territorio el cumplimiento de cualquier determinación que se entendiera lesiva de su costumbre, incluso potencialmente.»

\section{El pactismo en la Provincia de Gipuzkoa}

El modelo es similar en el caso de Gipuzkoa donde, como en todo el País, el pactismo estaba profundamente arraigado en el entramado foral. El punto de partida sería el año 1200, en el que tuvo lugar la incorporación de la Provincia a Castilla. Todo ello se llevaría a cabo mediante un pacto con Alfonso VIII, abandonando así Gipuzkoa la órbita navarra, descontenta por algunos desafueros cometidos por el monarca navarro Sancho el Fuerte. Esta la versión clásica, defendida por Garibay ${ }^{13}$ y que pasó

13 Sin olvidar la relevancia de Juan MartínEZ DE ZALdiBia, (Suma de las cosas cantábricas y guipuzcoanas. —c. 1560—, ed. de Fausto Arocena, Diputación de Gipuzkoa, San Sebastián, 1944), el autor más importante a estos efectos es Esteban de GARIBAY y ZAMALLOA y su célebre Compendio historial (Los Quarenta libros del Compendio Historial de las Chrónicas y Universal Historia de de todos los Reynos de España, —ed. de Chrisophoro Plantino, Ambres, 1571; o en la edición de Sebastián de Cormellas, Barcelona, 1628). Sobre este asunto v. Arocena, F., Guipúzcoa en la Historia, Madrid, Ed. Minotauro, 1964, pp. 73 y ss. 
a formar parte de la tradición foral. Ante la existencia de otras versiones que negaban la entrega voluntaria y pactada al monarca castellano y aludían a una conquista militar del territorio por su parte, los defensores de la foralidad reaccionaron siempre del mismo modo, esto es, defendiendo la incorporación voluntaria y pactada de Gipuzkoa a la Corona castellana, manteniendo dicha Provincia sus fueros, costumbres y libertades.

En el libro que José Angel Achón Insausti ${ }^{14}$ ha dedicado recientemente a las Memorias de Garibay, se contiene una reflexión acerca de este asunto que, frente a las encendidas polémicas historiográficas a favor de una u otra tesis, destaca por su ecuanimidad y nos permite explicarnos algunas cosas que de otro modo nos resultarían difíciles de entender. Al referirse al tema del origen pactado en las relaciones entre el Rey y la Provincia, escribe: «... Independientemente de la veracidad histórica del suceso, parece indudable que Garibay y los guipuzcoanos están proyectando hacia el pasado la idea que ellos mismos tenían de esa relación en el XVI. Téngase en cuenta que esa idea pudo irse forjando durante la Baja Edad Media, gracias precisamente a esos juegos sucesivos de confirmaciones de privilegios tan habituales en la época. Téngase además presente que no estamos ante una cultura —como la nuestra-que conciba una separación radical entre el presente y el pasado y, por tanto, tales proyecciones resultaban "lógicas". Esta concepción pactada de la relación con el rey, acentuaba la visión de éste como protector - recuérdese que es la figura de la encomendación la que utiliza Garibay, y Zaldibia insiste en la voluntariedad-y tendería a eliminar cualquier tentación intervencionista del monarca o de sus agentes. A cambio de fidelidad y determinados servicios (recuérdese siempre la estratégica situación fronteriza de la Provincia), los guipuzcoanos veían protegidas sus libertades, como precisamente habría demostrado la actuación real en los episodios banderizos. Nos encontramos aquí, en la idea del pacto, con una reafirmación de talante claramente político de la percepción comunitaria...»

\section{El pactismo en la Provincia de Alava}

También en Alava, vamos a encontrar el mismo tipo de planteamientos, porque el pactismo es consustancial al entramado foral alavés. De hecho, todo él se fundamenta en la «Voluntaria entrega»o

14 Achón InSAusti, J.A., Las «Memorias» de Esteban de Garibay y Zamalloa, Arrasateko Udala, 2000, pp. 41-42. 
«Pacto de Arriaga» de 2 de abril de 1332. Tras la conquista de Vitoria en 1200 por parte del monarca castellano Alfonso VIII, el pacto entre el Territorio alavés y el Rey de Castilla se estableció mediante dicho texto, que supuso la autodisolución de la Cofradía de Arriaga y la integración de la Provincia de Alava en Castilla, bajo el reinado de Alfonso XI, pero, eso sí, de forma «voluntaria», a cambio de conservar sus fueros, franquicias y libertades. Como ocurre casi siempre en estos casos, existen teorías contrapuestas a la hora de valorar la importancia de la «Voluntaria entrega». La concepción tradicional de la Cofradía de Arriaga desde Landázuri ${ }^{15} \mathrm{y}$, en general, las tesis forales tradicionales, han sido defendidas con uñas y dientes por las autoridades alavesas, quienes han sostenido desde siempre que la «Voluntaria entrega» fue un pacto o contrato entre dos sujetos políticos soberanos: la Cofradía de Arriaga y el Rey. Sin embargo, no faltan otras tesis que han defendido que se trata de una renuncia unilateral de la Cofradía a sus atribuciones mediante una transacción que pretendía obtener la salvaguarda de algunos de los derechos de sus miembros por parte del Rey.

Pero como ocurre en el caso vizcaíno y en el guipuzcoano, lo verdaderamente importante es lo que ha quedado en el subconsciente alavés. Pues bien, la percepción que ha sobrevivido en su subconsciente colectivo es que se trata de una relación pactada y así fue sentida y aceptada por todos, no sólo por las instituciones alavesas, que afirmaban que Alava (como dice, por ejemplo, el Acuerdo de las Juntas Generales en sesión celebrada en Vitoria el 22 de noviembre de 1656): «... siendo libre sin reconocer superior en lo temporal se entregó a la Corona Real de Castilla por su mera y espontánea voluntad», sino incluso por la propia Corona. Hasta el extremo de que el propio Llorente, nada sospechoso de comulgar con la idea del pacto en este asunto, cita una Real Cédula de Felipe IV, de 2 de abril de 1644, en la que se viene a reconocer ese carácter pactado, en sintonía con lo que se pensaba y proclamaba en el País: "... que siendo la dicha provincia libre, no reconociente superior en lo temporal y gobernándose por propios fueros y leyes, se entregó de su voluntad al rey don Alfonso el onceno con ciertas condiciones y prerrogativas...».

15 Landázuri Romarate, J.J. de, Historia civil de la M.N y M.L. Provincia de Alava, deducida de autores originales y documentos auténticos, Vitoria, 1798. Pueden consultarse su Historia de Alava, Diputación Provincial de Alava, Vitoria, 1926-1930 o la versión de su Historia General de Alava, editada por la Editorial de la Gran Enciclopedia Vasca, Bilbao, 1973. 


\section{La pervivencia del pacto en la tradición foral de Bizkaia, Gipuzkoa y Alava}

Como ha escrito Gregorio Monreal ${ }^{16}:$ «... Destacadas y significadas instituciones político-administrativas del Medievo no han conseguido ser incorporadas al pensamiento político de las comunidades en las que se enraizaron. Desaparecieron sin recibir la adhesión emocional de las generaciones subsiguientes, sin convertirse en elementos de referencia y de identificación colectiva. Y refiriéndose al caso alavés dice: «De ahí que debamos hacernos algunas primeras preguntas: ¿Por qué razón la Cofradía de Arriaga y el Convenio de incorporación a la Corona se han abierto un lugar en la mente y en el corazón de los alaveses modernos y contemporáneos, y de los vascos, en general? ¿Por qué estos elementos han contribuido a catalizar una conciencia de colectividad?»

Hay un viejo refrán vasco que dice: «Izena duen orok, izana du», es decir, «Todo lo que tiene nombre, existe». Por mucho que se intente descalificar este tipo de contenidos tradicionales de la foralidad y se diga que se trata de meros mitos que intentan justificar privilegios de los territorios forales en relación con otros territorios de régimen no foral o común, debe haber algo en todo esto mucho más profundo, para que subsistiesen tanto tiempo y fuesen aceptados por vascos y no vascos. Creo que ocurre algo similar a lo que sucede con los símbolos de la mitología vasca. Julio Caro Baroja, en el Prólogo a la «Mitología vasca» del P. Barandiarán ${ }^{17}$, escribía: «... Barandiarán nos ha informado como nadie de las ideas cardinales que dominan en las mentes que aceptan como cosa real mitos semejantes. La principal de ellas, a mi juicio, es la de que todas las cosas que tienen nombre existen».

$\mathrm{Si}$ una idea ha sido capaz de permanecer en la mente de una comunidad hasta el extremo de hacerse un hueco en ella y de ser considerada como algo sustancial a la misma, es que esa idea responde a algo que, de un modo u otro, ha existido. Y algo muy profundo ha existido desde siempre en el subconsciente de nuestro pueblo acerca del pactismo. No se trata de algo que sólo se enuncia de vez en cuando, sino que es algo que se interioriza y que se siente como inherente a nuestro modo de ser, a nuestra esencia. Por eso va más allá del mero mito y se ha convertido

16 Monreal Zía, G., «Incidencia de las instituciones públicas de Alava del medievo....», op. cit., pp. 614-615.

17 Caro Baroja, J., en el prólogo a Barandiarán, J.M., «Mitología vasca», Txertoa, San Sebastián, 1996, p. 11. 
en elemento capital de la foralidad. Y así ha sido percibido por propios y extraños durante mucho tiempo.

Por ello, cuando a partir del siglo XVIII se intente combatir la especificidad de los territorios forales en aras de una uniformización muy poco respetuosa con el «statu quo» vigente hasta entonces, el primer elemento que se intentará combatir, será el del pactismo. Parafraseando a Lacarra, todo lo que se salía de la uniformidad peninsular bajo las leyes de Castilla fue considerado como fuero o privilegio. Frente a la ley, el privilegio. De este modo, como ha dejado escrito algún ilustre autor, «el privilegio pierde su etimología de «propia ley» para pasar a ser sinónimo de favoritismo y falta de equidad». En este sentido, y refiriéndose a los Fueros vizcaínos, Adrián Celaya Ibarra ha abundado en la idea de que los Fueros no eran privilegios ya que eran normas generales y abstractas que se aplicaban a todos los habitantes del Señorío y no a determinados grupos de personas ${ }^{18}$. El privilegio en sentido peyorativo nace cuando se discrimina o deja en condición inferior a quienes no gozan de ellos, no cuando constituyen la ley común y general aplicable a todos los habitantes del territorio. Así, los Fueros no eran privilegios odiosos sino la ley general para todos los habitantes del territorio. Sin embargo, es esa consideración peyorativa de los fueros como privilegios la que subyace en los Decretos de Nueva Planta de Felipe V. Esa contraposición entre ley y fuero o privilegio aparece ya, como dice Lacarra ${ }^{19}$, en la terminología empleada por Felipe V en su Decreto de 29 de junio de 1707: «he juzgado por conveniente (así por esto como por mi deseo de reducir todos mis Reynos de España a la uniformidad de unas mismas leyes, usos, costumbres y Tribunales, gobernándose todos por las leyes de Castilla tan loables y pausibles en todo el Universo) abolir y derogar enteramente como desde luego doy por abolidos y derogados, todos los referidos fueros, privilegios, práctica y costumbre en los referidos Reynos de Aragón y Valencia» (Nov. Recop. de las Leyes de España, Lib. III, tít. 3, Ley 2).

Si bien Bizkaia, Gipuzkoa, Alava y Navarra acertaron al adherirse a la causa de Felipe V en la guerra de sucesión española (que a la postre sería la que obtendría la victoria) y por eso fueron respetados sus «Fueros», esta contraposición entre ley y fuero, entendido este último como privilegio, fue abriéndose paso a lo largo del siglo XVIII y acabó por amenazar también a dichos territorios. Así, se empezaron a atacar los

\footnotetext{
18 Celaya Ibarra, A., Humanismo y libertad en el Fuero de Bizkaia, op. cit., p. 16.

19 LACARRA, J.M., «Estructura político-administrativa de Navarra antes de la Ley Paccionada», op. cit., pp. 246-247 y nota al pie n. ${ }^{\circ} 42$.
} 
fundamentos del sistema (y uno de los más importantes era, como estamos viendo, el del pactismo), para intentar arrumbar todo el edificio foral. Es en este contexto, en el que debe entenderse la labor de zapa de nuestra foralidad de historiadores como Martínez Marina, Traggia, González Arnao y, sobre todo, Llorente. Sus tesis eran torpedos dirigidos directamente contra la línea de flotación de la foralidad, su influencia fue enorme durante todo el siglo XIX y siguió presente incluso cuando, tras la finalización de la guerra carlista en 1876, se estaba debatiendo en las Cortes españolas la abolición foral, como lo atestigua con gran pesar, por cierto, aquel alavés y vasco benemérito y gran defensor de la foralidad que fue D. Mateo Benigno de Moraza ${ }^{20}$.

Llorente no perdió ocasión de desmitificar la foralidad clásica y cada uno de sus contenidos sustanciales. En lo que se refiere al pactismo, y refiriéndose a Bizkaia escribió: «La Provincia de Vizcaya no fue más feliz que las otras dos vascongadas en legislación. No la tuvo propia, sin embargo de quanto se ha querido decir sobre los pactos supuestos entre ella y su primer señor. Pudo haber algunos si el señorío comenzó por behetría y no por gobierno; pero serian de la misma esfera que otros qualesquiera del reyno de Astúrias, cuya naturaleza se percibe por el fuero viejo de Castilla, cartas de población, y otros monumentos antiguos. Los usos, costumbres, albedríos y fazañas eran todo el cuerpo legislativo no escrito de Vizcaya hasta el siglo XII, en que algunos pueblos recibieron fueros particulares» ${ }^{21}$.

Esta misma tendencia se aprecia en todo el Diccionario geográfico-histórico de España de la Real Academia de la Historia ${ }^{22}$. Así en su «voz» referida a Bizkaia, González Arnao dice: «... Por la serie de

${ }^{20}$ En su famosa intervención en el Congreso en defensa del régimen foral, cuando se estaba debatiendo el proyecto de Ley que daría lugar a la Ley abolitoria de 21 de julio de 1876, decía. «Yo, señores diputados, no debiera decir nada de Llorente. Mas es que Llorente vive; es que su imagen se reproduce; es que todos los que nos atacan se acogen a él; es que su libro está en manos de todos nuestros enemigos..., es que se copian sus razonamientos...» (Diario de Sesiones del Congreso, 1876-1877, V., p. 3008).

${ }^{21}$ Llorente, Noticias..., op. cit., 2. ${ }^{\text {a }}$ parte, cap. IV, pp. 33-34.

22 El tema ha sido bien estudiado por el profesor J.M. PoRTILlo VALdÉs en su artículo «Momento preconstituyente, debate constitucional: las Provincias exentas y la Monarquía Hispana en la crisis del Antiguo Régimen», en Cano Bueso, J. (ed.), Materiales para el estudio de la Constitución de 1812, Ed. Tecnos/Parlamento de Andalucía, Madrid, 1989, pp. 647-658. En cuanto a las referencias al Diccionario geográfico-histórico de España por la Real Academia de la Historia, Madrid, 1802, que aperecen citadas en mi texto, corresponden a las voces relativas a los territorios forales que se encuentran en la Sección I (que comprende el Reino de Navarra, Señorío de Bizkaia y Provincias de Gipuzkoa y Alava), Tomo II, pp. 507-509 (Bizkaia) y Tomo I, pp. 340-343 (Gipuzkoa) y p. 44 (Alava). 
sucesos que se han referido acerca de cada uno de los pretendidos y los verdaderos señores de Vizcaya, se ve con la mayor claridad, quan cierto es el concepto que desde luego hemos indicado, de que ni es tan antigua como se supone la dominación de una determinada familia en aquella provincia, ni ha habido jamás la independencia y soberanía absoluta que han querido atribuirse a aquella dominación... Véase, pues, quan lejos está de poderse hallar establecido un sistema legal de constitución, llamémosle así, un derecho público que arreglase los intereses y relaciones recíprocas entre señor y súbditos, entre el cuerpo de la provincia y quien lo gobernaba, qual se quiere suponer existió siempre en aquel país.»

Sin embargo, en la voz referida a Gipuzkoa, Abella es más prudente. Al referirse a la integración de la Provincia en la Corona de Castilla en 1200, hace referencia primero a la tesis foral tradicional de Garibay, añadiendo después una serie de teorías que defienden la tesis de la simple conquista. A la hora de hacer balance y de dar su opinión, dice: «... En vista de tan repetidos testimonios de los escritores que trataron del modo con que D. Alonso VIII adquirió la provincia de Guipúzcoa, no nos atrevemos a determinar si fue por conquista, como dan a enteder los autores citados, o si, lo que parece más regular, conociendo el riesgo próximo que la amenazaba, procuró evitar prudentemente el rigor de las armas, entregándose voluntariamente al rey de Castilla. Esto se ha creído siempre por nuestros historiadores, y así se dice en una real cédula de Fernando VI, su fecha en Buen Retiro a 8 de octubre del año de 1752, que se halla impresa en el suplemento de los Fueros de Guipúzoca». En esta última Real Cédula, se viene a reconocer, de hecho, la tesis tradicional ( «... con que siendo de libre dominio se entregó voluntariamente al Señor D. Alfonso VIII, llamado el de las Navas, el año 1200, baxo los antiguos fueros, usos y costumbres con que vivió desde su población...»).

Por último, Martínez Marina, autor de la voz «Alava» de ese mismo Diccionario, intenta desmontar la teoría foral tradicional relativa a la «Voluntaria entrega». Y así, escribe lo siguiente: «... Se dexa ver por quanto llevamos dicho hasta aquí, y parece quedar demostrado, que ni la tierra de Alava, ni sus señores particulares, ni la cofradía de Arriaga fueron libres, e independientes en algún tiempo; que no gozaron jamás de la facultad de elegir espontáneamente gobernador, gefe militar ni ministros de justicia, para exercer jurisdicción civil y criminal; que ésta era peculiar y privativa de los condes y merinos reales, subordinados a la suprema autoridad del soberano; y que la entrega voluntaria de la provincia, o hablando con más exactitud, de las tierras de señorío que había en ella, no fue otra cosa más que hacerse realengas». 
Inmediatamente, y para hacer frente a estas acometidas, todos los autores fueristas (Aranguren y Sobrado, Novia de Salcedo, etc.) se apresuraron a escribir obras que defendiesen el sistema tradicional foral. Y aunque durante el siglo XIX, el pactismo fue perdiendo fuerza como argumento (lo que resulta lógico si tenemos en cuenta que tenía que competir con los modernísimos dogmas del contrato social, la voluntad general y la soberanía popular), subsistió ${ }^{23}$. Y así, el Convenio de Bergara fue interpretado como un pacto que puso fin a la primera guerra carlista y eso explica también que en el período que se ha venido en llamar «neoforalidad» (el que comprende el período de tiempo comprendido entre la vigencia de las leyes de 25 de octubre de 1839 y de 21 de julio de 1876) se siguiese manteniendo la idea de que existía un régimen pactado entre las instituciones forales y el Gobierno central. Incluso tras la ley abolitoria de los fueros de Bizkaia, Gipuzkoa y Alava de 21 de julio de 1876, en la época de los Conciertos Económicos, la idea del «pacto» no sólo estuvo presente en la misma esencia del Concierto, como su propio nombre indica, o en las negociaciones para su modificación o renovación, sino también en los procedimientos establecidos para resolver las dudas a las que podía dar lugar la aplicación del mismo a través de normas como el Real Decreto de 6 de marzo de $1919^{24}$ o el Decreto de la II República española de 18 de mayo de $1931^{25}$.

El propio Estatuto del País Vasco de 6 de octubre de $1936^{26}$ fue fruto de un pacto. Y tras el largo y doloroso paréntesis de la dictadura franquista, los nacionalistas vascos defendieron inicialmente en el debate constitucional su teoría del «pacto con la Corona», que finalmente daría lugar a toda la discusión que concluyó con la aprobación de la célebre Disposición Adicional Primera de la vigente Constitución española de 1978 que «ampara y respeta los derechos históricos

${ }^{23}$ En opinión de Idoia EstornÉs ZuBIZARRETA, «... En un período en el que el optimismo revolucionario aspira a hacer tabla rasa del orden precedente, difícilmente podría convivir el viejo pactismo medieval, respetuoso de las servidumbres históricas, con ellos. Convertida en un absoluto sin fisuras, la voluntad general (soberanía popular) no tiene ninguna necesidad de ofrecer garantías con respecto a sus subordinados porque es imposible que el cuerpo quiera perjudicar a sus miembros». Pero como ella misma escribe: «... El pactismo, que siempre garantizó una cierta cuota de poder en manos de los súbditos y un derecho moral a la retroactividad, subsiste, sin embargo, merced a las diversas Restauraciones y cómo tópico justificatorio, en los alegatos foralistas del siglo XIX». (Ibidem, p. 430).

24 Publicado en la Gaceta de Madrid de 8 de marzo de 1919.

25 Publicado en la Gaceta de Madrid de 20 de mayo de 1931.

26 Publicado en la Gaceta de Madrid, Diario Oficial de la República, de 7 de octubre de 1936, n. $^{\circ} 281$. 
de los Territorios Forales». El propio Estatuto de Autonomía de Gernika de 1979, actualmente en vigor, no deja de ser un nuevo pacto. Como puede comprobarse, el pactismo ha sido desde siempre un elemento consustancial a nuestro sistema político y aún hoy en día continúa siéndolo.

\section{El pactismo en el Reino de Navarra}

Por lo que se refiere a Navarra, José M. ${ }^{a}$ Lacarra $^{27}$ ha escrito, en relación a su sistema político foral tradicional, que una de sus características más notables es «... la instintiva repugnancia de los navarros a verse gobernados por poderes extraños al país. Si tienen que aceptar soberanías extrañas se esfuerzan en fijar y regular en lo posible las atribuciones que el nuevo poder soberano ha de tener sobre los navarros. Es lo que se ha calificado de espíritu pactista...».

Cuando, como afirma Monreal ${ }^{28}$, se produce la instauración de la nueva dinastía de la casa de Champaña en Navarra, ésta «... tropieza con una mentalidad pactista, asentada sobre el mito fundacional del pacto entre la monarquía y el reino que se había establecido de acuerdo con el prólogo de los denominados Fueros de Sobrarbe "cuando ganaban las tierras sin rey los montaynneses" ». El resultado fue, en palabras de Lacarra, la estructuración del Estado en una monarquía basada en el pacto entre el Rey y el Reino. De este modo, el Rey de Navarra sólo es «alzado», esto es, reconocido como Rey, si se somete previamente a las leyes del País. El Rey jura, y sólo después de su juramento es reconocido y jurado por sus súbditos. En su juramento se compromete a respetar los fueros y a mejorarlos («amejorarlos»), a deshacer las violencias, repartir el «bien de cada tierra» con las gentes del reino y no con extranjeros. Y si el Rey es extranjero, sólo podrá nombrar para cargos de gobierno a un máximo de cinco no navarros, no podrá administrar justicia - fazer Cort-, sin consejo de los ricos hombres naturales del reino, ni declarar la guerra, ni firmar la paz, ni acordar tregua ni «otro granado fecho o embargamiento del reino» sin consejo de doce ricos hombres o doce de los más ancianos sabios de la tierra.

Gregorio Monreal ha señalado cómo en el Fuero General de Navarra hay una descripción pormenorizada del contenido del pacto político,

${ }^{27}$ LACARra, J.M., «Estructura político-administrativa de Navarra antes de la Ley Paccionada», op. cit., p. 231.

28 Monreal Zía, G., Ibidem, pp. 620-621. 
materializado en el acto del juramento recíproco. De este modo, si los estamentos se comprometen a cumplir las obligaciones que les corresponden, el Rey, en juramentos sucesivos, adquiere el deber de respetar el status preestablecido de cada uno de los cuerpos del reino y, en general, se compromete a "que en todos sus días tenga a todo el pueblo en sus fueros e non los apeiore».

Esta concepción pactista subsistió tras la incorporación del Reino de Navarra a Castilla en el siglo XVI, que, según afirman las leyes 33 (Título 8..$^{\circ}$ ) y 59 (Título 2. ${ }^{\circ}$ ) del Libro I de la Novísima Recopilación, se hizo "por vía de unión aeqüe-principal, reteniendo cada uno su naturaleza antigua, así en leyes como en territorio y gobierno», de tal manera que Navarra «... quedó y permaneció Reino de por sí, rigiéndose por sus fueros, leyes, reglamentos, usos, costumbres, franquezas y libertades».

Sin embargo, no faltó también la acometida contra esta teoría y así Traggia $^{29}$, en la voz correspondiente a Navarra del Diccionario geográfico-histórico de España, aun reconociendo el carácter pactado mientras Navarra fue reino independiente, no hace lo mismo al referirse al período de tiempo posterior a la incorporación de Navarra a Castilla en tiempos de Fernando el Católico: «... La tercera época y la última es la actual, que puede llamarse de privilegio, supuesto que el rey católico y sus sucesores han conservado substancialmente su antigua constitución, a pesar de que la privación de Juan de Labrit y la fuerza de las armas le abrieron el camino para la posesión de la corona de Pamplona. No habiendo llamado los navarros al rey católico, y careciendo de fuerza para sostener sus leyes, admitieron al exército del rey después de una ligera resistencia, y baxo las condiciones que éste tuvo a bien otorgarles por su beneficiencia, y por creerlas útiles al bien del estado, rechazando las que no le parecieron convenientes. Así la obligación que hacen los reyes es voluntaria en su raíz, y voluntario su juramento, y no nacido de otra causa extraña que precise a su observancia».

Sin embargo, en Navarra se ha mantenido siempre contra viento y marea este carácter pactado. Y tan arraigado está, que no sólo perduró hasta el siglo XIX (estando como está en la base de la Ley Paccionada de 16 de agosto de 1841 — cuya denominación sigue haciendo referencia al «pactismo»-), sino que se extiende incluso hasta hoy, máxime si tenemos en cuenta el peculiar modo en que Navarra se ha insertado en el

29 Real Academia de Historia, Diccionario geográfico-histórico de España, op. cit., Sección I, Tomo II, voz «Navarra», p. 142. 
sistema de organización territorial establecido por la Constitución española de 1978, a través de la actualmente vigente Ley Orgánica 13/1982, de 10 de agosto, de Reintegración y Amejoramiento del Régimen Foral de Navarra, o su peculiar sistema financiero y tributario, que responde al sistema de Convenio Económico y cuyo carácter pactado aparece hasta en su propia denominación.

\section{Reflexión final}

A lo largo de este trabajo he intentado describir lo que supuso el pactismo para nuestra tradición foral. El pacto en el interior de cada Territorio Foral, entre los distintos Territorios Forales y en las relaciones de éstos con la Corona ha sido una constante en nuestra historia y se ha mantenido en los Territorios Forales como una característica distintiva de nuestro sistema, a diferencia de otros territorios donde se perdió definitivamente. Aprendamos la lección de nuestros antepasados y busquemos puntos de encuentro entre todos y para todos, respetando siempre las particularidades de cada uno. El pacto se impone, así, como algo consustancial a nuestra peculiar forma de ser. Como he tenido ocasión de escribir recientemente en otro lugar ${ }^{30}$, ése ha sido siempre el camino para una convivencia razonable entre todos y con todos. La historia de nuestro derecho es maestra, no olvidemos, pues, sus lecciones.

30 Larrazábal Basáñez, S., «La cultura del pacto en el Derecho Público Vasco a lo largo de su historia», Boletín de la Academia Vasca de Derecho, Año I, n. ${ }^{\circ} 0$ (junio 2003), pp. 37-47. 